Pub, Mat. UAB

vol. 30 No 1 Maig 1986

\title{
STATE DIAGRAM FOR OPERATORS WITH NULL SPACE OR CONULL SPACE IN AN IDEAL OF BANACH SPACES
}

\section{Teresa Alvarez}

\section{1.- Introduction}

Let $\mathrm{B}$ be the class of all Banach spaces; the scalar field $\mathrm{K}$ is either the real field or the complex field. All operators acting between Banach spaces which appear in this article are supposed to be linear. For $X, Y \in B, \mathcal{L}(X, Y)$ is the space of all operators from $X$ into $Y$, the class. of all operators from $X$ into $Y$ with dense domain is denoted by $\mathcal{L}_{D}(X, Y), I_{X}$ denotes the identity operator on $X, J_{X}$ is the embedding map of $X$ into $X{ }^{\prime \prime}$, and $X \subset_{q} Y$ means that $X$ is a quotient space of $Y$. For $T \in \mathcal{L}(X, Y), D(T), N(T)$ and $R(T)$ will denote the domain, null space and range of $T$ respectively, and we also write $\operatorname{CON}(T):=Y / R(T)$, $\overline{\mathrm{CON}}(\mathrm{T}):=\mathrm{Y} / \overline{\mathrm{R}}(\mathrm{T})$, while $\alpha(\mathrm{T}), \beta(\mathrm{T})$ and $\overline{\mathrm{B}}(\mathrm{T})$ will denote the dimension of $N(T), \operatorname{CON}(T)$ and $\overline{\operatorname{CON}}(T)$ respectively. We shall consider

$$
\begin{aligned}
\operatorname{NES}(X, Y): & =\{\mathrm{T} \in \mathcal{L}(\mathrm{X}, \mathrm{Y}): \mathrm{T} \text { is normally solvable }\} \\
\mathrm{L}(\mathrm{X}, \mathrm{Y}): & =\{\mathrm{T} \in \mathcal{L}(\mathrm{X}, \mathrm{Y}): \mathrm{T} \text { is bounded }\}
\end{aligned}
$$

Let $A$ be an ideal of Banach spaces. For informations and notations about operator ideals and space ideals we refer to [5]. We consider the ideals, S, R or F, the ideals of all separable, reflexive or finite dimensional Banach spaces respectively.

Some notations will be used without explanation because their meaning is obvious.

In this paper we obtain a state diagram of a linear operator with dense domain between Banach spaces and its conjugate operator, and we prove that this diagram is complete.

\section{2. "GENERALIZED" CLASSIFICATION OF ( $\mathrm{T}, \mathrm{T}$ "): STATE DJAGRAM}

2.1. THEOREM. Let $A$ be an ideal and $T \in \mathcal{L}_{\mathrm{D}}(\mathrm{X}, \mathrm{Y})$. Then: 

is strict. If, in addition $T \in N S$, then $a(T)={ }_{B}\left(T^{\prime}\right)$.

(ii) Let $A$ be a completely symmetric ideal, then:

(ii $) N\left(T^{*}\right) \in A$ if and only if $\overline{\operatorname{CON}}(T) \in A$

(ii $\left.{ }_{2}\right) T \in S S S: N(T) \in A$ if and only if $\operatorname{CON}\left(T^{\prime}\right) \in A$.

$\left(i i_{3}\right)$ Suppose $A$ surjective, if $\overline{\operatorname{CON}}\left(T^{*}\right) \in A$ then $N(T) \in A$.

For arbitrary ideals, the properties are not valid, in general.

Proof. (1) It is an obvious consequence of the duality relations,

$$
\left.\overline{\operatorname{CON}}(T)^{\prime}: \overline{\mathrm{R}(\mathrm{T}}\right)^{\circ}=\mathrm{N}\left(\mathrm{T}^{\prime}\right) \text {, }
$$

$\left.\left.N(T)^{\prime}=X^{*} / N(T)^{\circ}=\left(X^{\prime} / \overline{R\left(T^{T}\right.}\right)\right) /\left(N(T)^{\circ} / \overline{R\left(T^{\prime}\right.}\right)\right) \subset \bar{q} \overline{\operatorname{CoN}}\left(T^{\prime}\right)$

To see that, in general, the inequality $a(T) \leq \bar{B}\left(T^{\prime}\right)$ is strict

we define $T \in L(1)$ by $T\left(a_{1}, a_{2}, \ldots, a_{n}, \ldots\right)=\left(0, a_{1}, 2^{-1} a_{2}, \ldots, n^{-1} a_{n}, \ldots\right)$, $\left(a_{n}\right) E 1$. Its conjugate operator is $T^{\prime}\left(B_{n}\right)=\left(n^{-1} B_{n+1}\right),\left(B_{n}\right) E_{\infty}$. It is obvious that $N(T)=\{0\}, 1_{\infty} / C_{0} \underset{q}{C O N}\left(T^{\prime}\right)$ since $R\left(T^{\prime}\right) C c_{0}$. Clearly $\overrightarrow{C O N}\left(T^{\prime}\right) \&$ since if $l_{\infty} / c_{0} \in R$ then $c_{0}$ has a subspace isomorphic to $1_{\infty}$; that contradicts $c_{0} \in S$ and $1_{\infty} \& \mathrm{~S}$.

(ii ${ }_{1}$ ) It is suffices to notice that $N\left(T^{\prime}\right)=\overline{C O N}(T) \cdot$ and that $A$ is completely symmetric.

$\left(\mathrm{ii}_{2}\right)$ It $\mathrm{T} \in \mathcal{S}^{\prime} S$ then $\mathrm{N}(\mathrm{T})$ ) $\simeq \operatorname{CoN}\left(\mathrm{T}^{\prime}\right)$.

$\left(\mathrm{ii}_{3}\right)$ Note that $\mathrm{N}(\mathrm{T}) \cdot \underset{\mathrm{q}}{\mathrm{C}} \overline{\operatorname{CON}}\left(\mathrm{T}^{\prime}\right)$, A surjective and completely, symmetric.

For arbitrary ideals, the above results are not guaranteed;

for example, if $D:=\left\{X \in B: J_{X} X\right.$ is complenented in $\left.X^{\prime} '\right\}, T_{1}, T_{2}$ the null maps on $1, c_{0}$ respectively, then

$$
\begin{aligned}
& N\left(T_{1}^{\prime}\right)=1_{\infty} \notin S, \operatorname{CoN}\left(T_{1}\right)=1 \epsilon S \\
& N\left(T_{2}^{\dagger}\right)=1 \in D, \operatorname{CoN}\left(T_{2}\right)=c_{0} \notin D, \\
& N\left(T_{1}^{\prime}\right)=1 \in S, \operatorname{CoN}\left(T_{1}^{\prime}\right)=1_{\infty} \notin S, \\
& N\left(T_{2}\right)=c_{0} \notin D, \operatorname{CoN}\left(T_{2}^{\prime}\right)=1 \in D .
\end{aligned}
$$

We now introduce the rollowing classification of

$T \in C_{D}(X, Y)$. 
$I: a(T)<\infty$.

II : $\alpha(T)=\infty$ and $N(T) \in A$.

III: $a(T)=\infty$ and $N(T) \notin A$.

$1: \bar{B}(T)<\infty$.

$2: \bar{B}(T)=\infty$ and $\overline{\mathrm{CON}}(\mathrm{T}) \in \mathrm{A}$.

$3: \bar{B}(T)=\infty$ and $\overline{\mathrm{CON}}(\mathrm{T}) \notin \mathrm{A}$.

By combining these possibilities we obtain nine different situations. This classification scheme may now be applied to the conjugate $\mathrm{T}^{\prime}$ of $\mathrm{T}$.

The properties of the (2.1) theorem on the language of the previous classification can be witten as:

$\mathrm{T}^{\prime} \in \mathrm{I} \Leftrightarrow \mathrm{T} \in \mathrm{I}$

$\mathrm{T} \notin \mathrm{I} \Rightarrow \mathrm{T} \notin 1$

$T \in \mathscr{N S}: T \in I \Leftrightarrow T^{\prime} \in 1$

A completely symetric: T'EIIT $\Longleftrightarrow T \in 3$

A completely symetric and surjective: $T \in I I I \Rightarrow T^{\prime} \in 3$

A completely symmetric and $T \in N S$ : $T \in I I I \Longleftrightarrow T \cdot \in 3$.

we shall proceed to construct a diagram. The shaded squares in the diagram correspond to states that are impossible by virtue of (2.1) theorem.

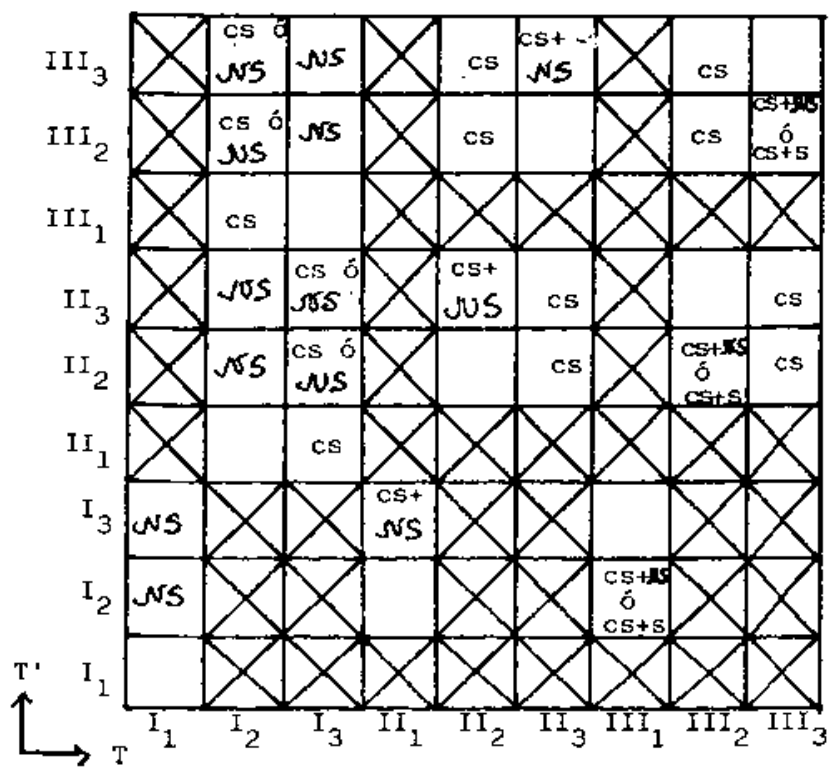


We analyse if the diagram is complete, so, we prove that a procedure to construct state examples of $\mathrm{L}(\mathrm{X}, \mathrm{Y})$ in the Taylor-Haldberg classification, introduced in 1962 by Goldbergand Thorp [2], is valid for our classification.

If $E_{1}, E_{2} \in B$ then the map

$h: h \in\left(E_{1} \times E_{2}\right)^{\prime} \longrightarrow\left(h_{1}, h_{2}\right) \in E_{1}^{\prime} \times E_{2}^{\prime}$ where $h_{1}\left(x_{1}\right):=h\left(x_{1}, 0\right)$, $h_{2}\left(x_{2}\right):=h\left(0, x_{2}\right), x_{i} E E_{i}, i=1,2$ is an isomorphic, thus we can identify $E_{1}^{\prime} \times E_{2}^{\prime}$ to $\left(E_{1} \times E_{2}\right)$, through the rormula

(\$) $\left(h_{1}, h_{2}\right)\left(x_{1}, x_{2}\right):=h\left(x_{1}, x_{2}\right):=h_{1}\left(x_{1}\right)+h_{2}\left(x_{2}\right) \in k$ where $\left(x_{1}, x_{2}\right) \in E_{1} \times E_{2}$.

For $r_{1} \in \mathcal{L}_{0}\left(X_{1}, Y_{1}\right), T_{2} \in \mathcal{L}_{D}\left(X_{2}, Y_{2}\right)$ it is possibleidentify $T_{1}^{\prime} \times T_{2}^{\prime}$ to $\left(T_{1} \times T_{2}\right)^{\prime}$ by using the (\$) formula to consider ( $\left.T_{1}^{\prime} h_{1}, T_{2}^{\prime} h_{2}\right)$ as an element of $\left(X_{1} x_{2} X^{\prime}\right.$. Also it is clear that if we define the product between two states of our classification by using the formula $\left(A_{a}, B_{b}\right) \times\left(C_{c}, D_{d}\right):=\left(\max (A, C)_{\max }(a, c), \max (B, D) \max _{(b, d)}\right)$ then the state of the operator $T_{1} \times T_{2}$ is the product of the $T_{1}$ and $T_{2}$ states.

\section{(2.2) THEOREM. The state diagram for $\left(T, T^{\prime}\right)$ is complete.}

\section{Proof}

$\left(I_{1}, I_{1}\right)$ : Let $T$ be the identity operator in $X$.

$\left(I_{1}, I_{2}\right)$ : Let $A=R,\left(x_{i}\right)_{i \in I}$ a normalized Hamel basis of $I_{2}(N)$, $\left(e_{i}\right)_{i \in I}$ an orthonormal basis of $1_{2}(I)$. Define

$\mathrm{T}: \mathrm{D}(\mathrm{T}) \subset \mathrm{I}_{2}(\mathrm{I}) \rightarrow 1_{2}(\mathrm{~N})$

$$
e_{i} \longrightarrow \mathrm{Te}_{i}:=x_{i}
$$

where $D(T)$ is the linear span of the $e_{j} ' s . C l e a r l y D(T)$ is dense in $1_{2}(\mathrm{I}), R(\mathrm{I})=\mathrm{I}_{2}(\mathrm{~N})$ and $\mathrm{N}(\mathrm{T})=10 \mathrm{k}$. 
Let $\left(e_{n_{k}}\right)_{k \in N} \subset\left(e_{i}\right)_{i \in I}$ be a sequence of different vectors and $x_{m}^{n}:=\sum_{k=1}^{m} e_{n_{k}} / k^{2} \in D(T), m \in N$. Then $x_{m}^{n} \rightarrow x^{n}=\sum_{k=1}^{\infty} e_{n_{k}} / k^{2}$, $T x_{m}^{n} \rightarrow y^{n}:={ }_{k=1}^{\infty} x_{n_{k}} / k^{2} \in R(T)$ if $m \rightarrow \infty$; hence there exists $z^{n} \in D(T)$ such that $T z^{n}=y^{n}$, moreover $x^{n}-z^{n} \neq 0$ since $x^{\pi} \notin D(T)$, Consequently for $y \in D\left(T^{\prime}\right)$ we have that $\left\langle x^{n}-z^{n}, T^{\prime} y\right\rangle=0$ thus $x^{n}-z^{n} \in R\left(T^{\prime}\right)^{0}$. we can choose $\left(e_{n_{k}}\right)_{k \in N}\left(e_{i}\right)_{i \in I}$ disjoint sequences, thus for $n \in N$ we obtain $\left(x^{n}-z^{n}\right)$ $\in N^{C} R\left(T^{\prime}\right)^{\circ}$; moreover. $x^{n}-z^{n}$ are linearly independent, hence $\operatorname{dim} \overline{k\left(T^{\prime}\right)^{0}}=\infty$. Clearly $1_{2}(I) / \overline{R\left(T^{\prime}\right)} \in k$.

$\left(I_{1}, I_{3}\right)$ : Let $A=R$ and $T$ be the operator in (2.1) theorem $\left(I_{2}, I I_{1}\right)$ : Let $A$ be completely symmetric, $X \in F, Y \in A-F, T$ the null map from $X$ into $Y$.

$\left(I_{2}, I I I_{1}\right)$ : Let $A$ be non completely symmetric, $X \in F, Y \in A, Y \notin A, T$ the null map from $X$ into $Y$

$\left(I_{3}, I_{1}\right)$ : Let $A$ be non completely symmetric, $X \in F, Y \notin A, Y \notin A, T$ the null map from $X$ into $Y$

$\left(I_{3}, I I I_{1}\right)$ : Let $A$ be completely symetric, $M \subset x \notin A, M \in A, X / M \notin A, T$ the inclusion from $X$ into $Y$

$\left(I I_{1}, I_{2}\right)$ : In the example $\left(I_{2}, I_{1}\right)$ it suffices to replace $T$ by the conjugate operator.

(III $\left.{ }_{1}, I_{2}\right)$ : In the example $\left(I_{2}, I_{1}\right)$ it suffices to replace $T$ by the conjugate operator

(III $\left.I_{3}\right)$ : In the example $\left(I_{3}, I I I_{1}\right)$ it suffices to replace $T$ by the conjugate operator.

We can obtain the remaining allowed states by application of the previous procedure. 


\section{REFERENCES}

[1| S.GOLDBERG. Unbounded linear operators. MC Graw-Hil1, (1966).

[2] S. GOLDBERG, E.O. THORP. The range as range space for compact operators. J. Reine Angew. Math., 211, (1962), 113-115

[3] G.J.O. JAMESON. Topology and normed spaces. Chapman and Hall, (1974).

[4] J. LINDENSTRAuSS, L. TZAFRIRI. Classical Banach spaces I. Springer-Veriag, (1977).

[5] A. PIETSCH. Operator ideals. North-Holland, (1980).

[6] A.E. TAYLOR, C.J.A. HALBERG. General theorems about a bounded linear operator and its conjugate, J. Reine Angew, Math., 198, (2957). 93-111.

Rebut el 14 de novembre del 1985

\section{Teresa Alvarez}

Departamento de Teoria de Funciones

Facultad de Ciencias

Universidad de Santander

Santander, ESPAÑA 